\title{
Pseudoacromegaly - a differential diagnosis problem for acromegaly
}

\section{Rupert Spencer ${ }^{1}$, Pedro Marques ${ }^{1}$, Per Dahlqvist ${ }^{2}$, Mary N. Dang1, Gudmundur Johannsson² and Márta Korbonits ${ }^{1}$}

${ }^{1}$ Centre for Endocrinology, William Harvey Research Institute, Barts and The London School of Medicine and Dentistry, Queen Mary University of London

2 Department of Endocrinology, Institute of Medicine, Sahlgrenska Academy, University of Gothenburg, Grona straket 8, Sahlgrenska University Hospital, SE-413 45 Gothenburg, Sweden m.korbonits@qmul.ac.uk

\section{Introduction}

- Acromegaly is usually not a difficult condition to diagnose, if the suspicion of this disease has been raised. However, there are a few conditions presenting with some aspects of acromegaly or gigantism, but without excess of GH excess - pseudoacromegaly or acromegaloidism.

- Sotos syndrome (also known as cerebral gigantism syndrome) is a overgrowth condition characterized by four cardinal features: excessive growth during the childhood with advanced bone age; macrocephaly; characteristic facial appearance; learning difficulties. ${ }^{1}$

\section{Case report}

In 1974, a 10y girl presented with tall stature since infancy (>P97):

- She was $160 \mathrm{~cm}$ tall and weighed $60 \mathrm{~kg}$ (both over $97^{\text {th }}$ )

- Acromegalic features: large hands and feet (shoe size UK8/EU43), macroglossia, prognathism and deep voice (Figure 1)

- Her bone age was advanced (15y) and she had already a full set of permanent teeth

- Headaches and mild learning difficulties

- Pubertal development was corresponding to her chronological age (Tanner stage I)

- Sella X-ray and endocrine evaluation were normal

- Ethinylestradiol and medroxyprogesterone was started, with cessations of linear growth within $2 y$. No increase of shoe and glove size since the age of $15 \mathrm{y}$. Final height $=171 \mathrm{~cm}$.

Over the next 40 years:

- Acromegaly screening was initiated by different doctors on 2 more occasions, both negative

- Surgery for carpal tunnel syndrome and hallux valgus (31y)

- 3 unsuccessful IVF attempts

- Endometriosis: left salpingo-oophorectomy (31y) and total hysterectomy (34y)

- Radioiodine treatment for an hyperfunctioning thyroid nodule (34y)

Current presentation at age $49 y$ :

- Weight gain, sweating, sleep apnoea, headaches, joint pain, together with acromegalic facial features, lead to reassessment of GH axis and MRI scan - normal (Table 1)

- Genetic testing with a panel for macrocephaly/overgrowth syndrome genes: CUL4B, EZH2, GLI3, NSD1, PTEN and UPF3B.

- A heterozygous mutation in NSD1 gene known to cause Sotos syndrome was identified (c.6605G>C; p.Cys2202Ser) (Figure 2).

- DNA samples from her parents found no mutation, suggesting a de novo mutation.

\section{Discussion}

$>$ Sotos syndrome is a rare disorder, which diagnosis can be challenging and delayed.

$>$ Overgrowth, macrocephaly, acromegalic features and learning difficulties should raise suspicion for this condition, especially in those cases with normal GH axis. ${ }^{1}$

$>$ In addition to acromegaly, the differential diagnosis list includes several syndromes such as Weaver, Beckwith-Wiedeman, Simpson-Golabi-Behmel, Cowden, Malan syndrome, Fragile X-syndrome (in males), or Marshall syndromes. ${ }^{2}$

> NSD1 (Nuclear receptor binding SET Domain protein 1) gene contains 23 exons located on $5 q 35$, encoding a histone methyltransferase implicated in transcriptional regulation ${ }^{3}$. The variant we found was not previously described, but pathogenic mutations affecting the same cysteine residue have been reported ${ }^{4}$, strongly suggesting the pathogenicity of our variant.

The patient has agreed to the presentation of her case and all photographs

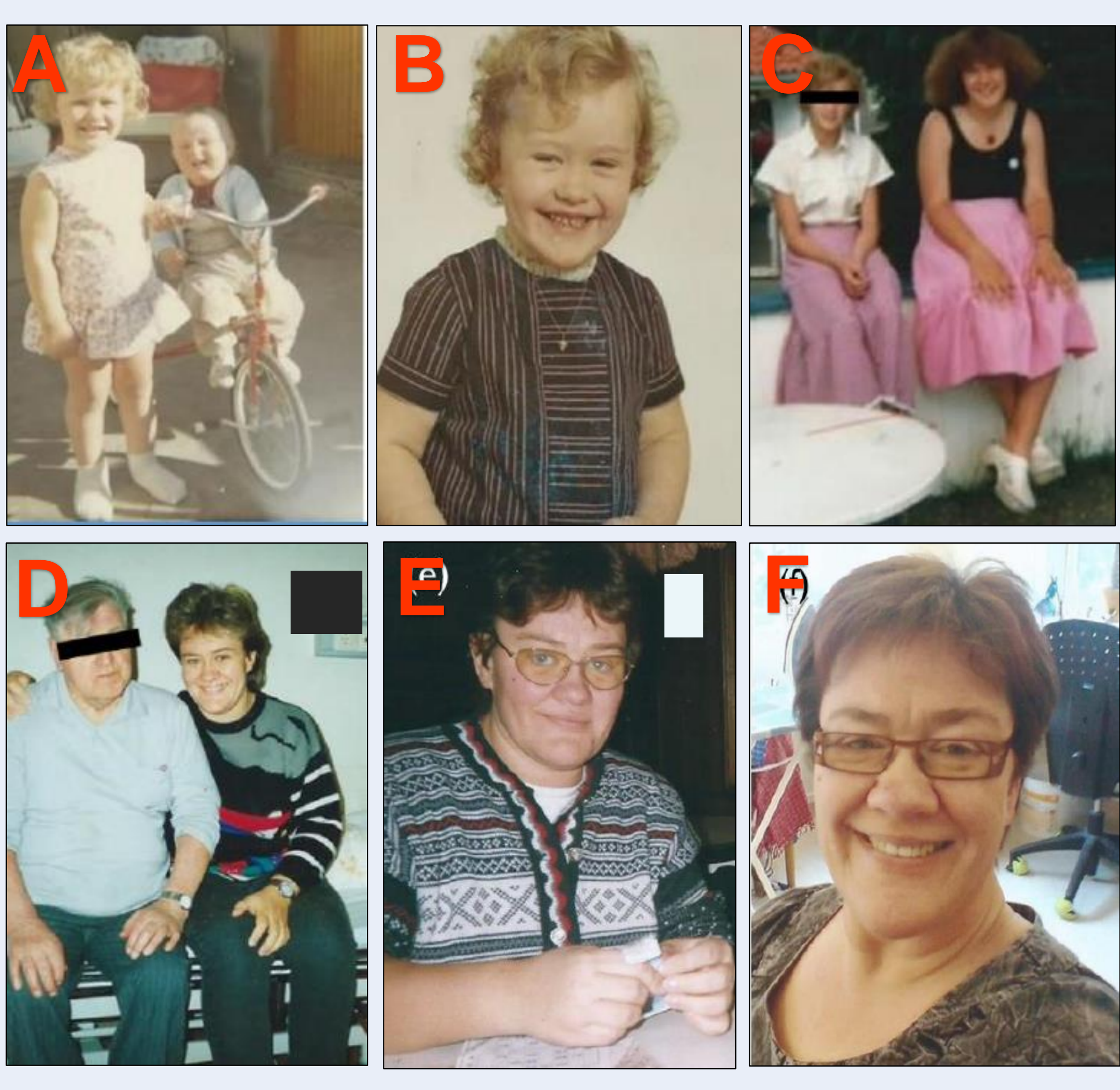

Figure 1: Patient's pictures at the ages of $3(\mathbf{A}), 5$ (B), 14 (C), 22 (D), 34 (E) and 45-years-old (F)

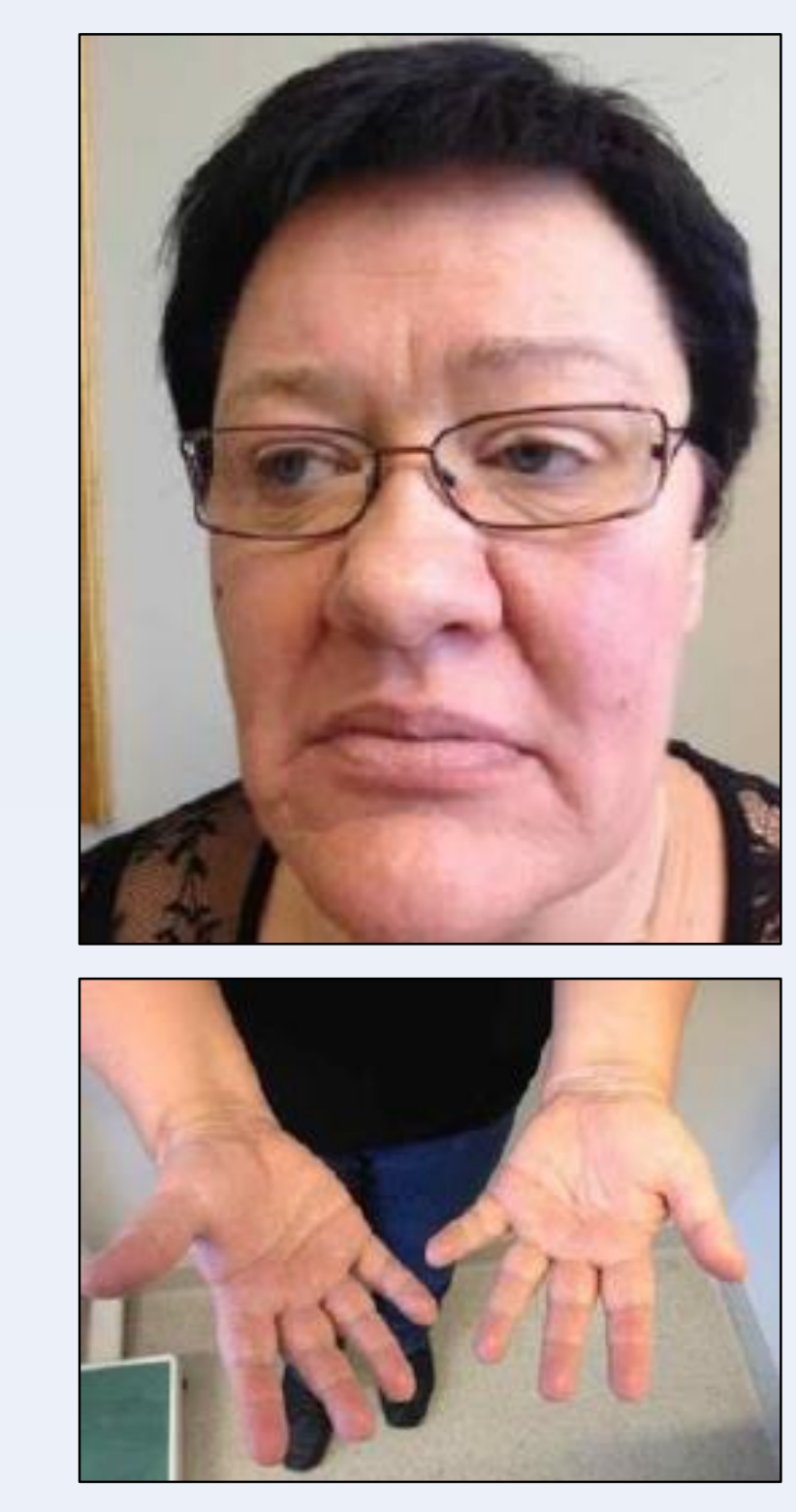

Height $(\mathrm{cm})$

Weight $(\mathrm{kg})$

$\mathrm{BP}(\mathrm{mmHg})$

Index finger diame Shoe size (UK/EU)

Haemoglobin $(\mathrm{g} / \mathrm{L}) \quad 145$

Fasting glucose $(\mathrm{mmol} / \mathrm{L}) \quad 5.4$

IGF-1 ( $\mu \mathrm{g} / \mathrm{L})$

GH day curve and OGTT

MRI sella

213 (54-307)

Normal

Normal

Table 1: Some clinical parameters, laboratory and imaging data from the last evaluation (prior to the genetic testing)

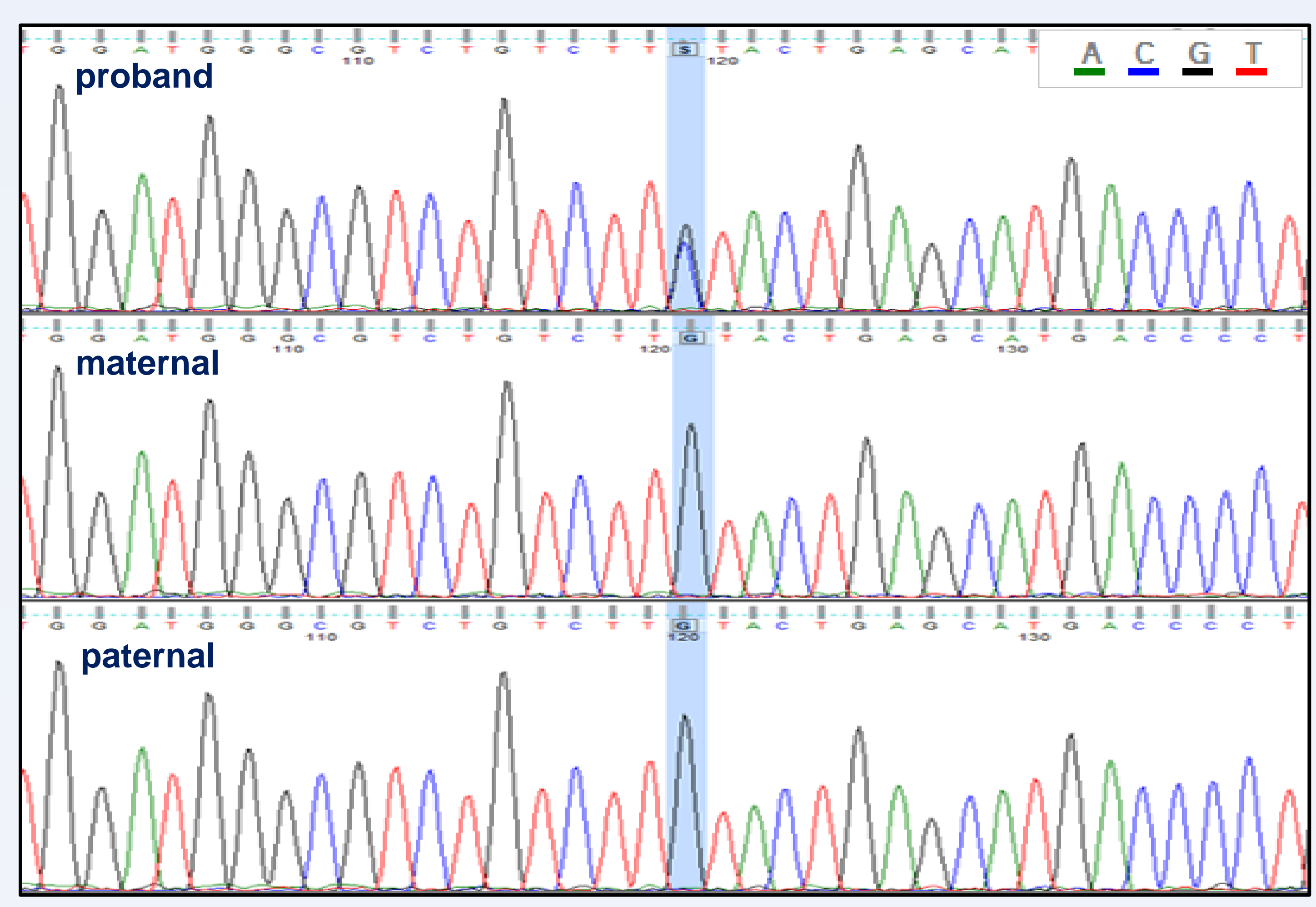

Figure 2: Sequencing electropherogram of NSD1 exon 23 from the patient (above) and her parents (below). The double peak (in blue) confirms the presence of a de novo heterozygous missense mutation at c.6605G>C (p.Cys2202Ser). No mutation was found in her mother and father.

Baujat G, Cormier-Daire. Sotos syndrome. Orph J Rare Dis 2007; 2:36.

Fickie M, Lapunzina P, Gentile J, et al. Adults with Sotos syndrome: Review of 21 adults with molecularly confirmed NSD1 alterations, including a detailed case report of the oldest person. Am J Med Genet Part A 2011; 155:2105-11.

3. Kurotaki N, Harada N, Yoshiura K, et al. Molecular characterization of NSD1, a human homologue of the mouse Nsd1 gene. Gene 2001; 279

Boer L, Kant S, Karperien M, et al. Genotype-phenotype correlation in patients suspected of having Sotos syndrome. Horm Res 2004; 62:197-207. 